\title{
Resiliência: Um novo paradigma que desafia a reflexão e a prática pastoral
}

\author{
Susana M. Rocca L.
}

\section{Introdução}

Os esforços das pessoas para vencer as adversidades e situações traumáticas acompanham a história do ser humano. No campo da Psicologia, durante um longo tempo e, especialmente no campo da psicologia, foi necessário descobrir e analisar as repercussões negativas, por exemplo, da ausência de figuras significativas que deveriam propiciar os cuidados necessários para o desenvolvimento físico, emocional e mental da criança, bem como as feridas provocadas por fatores como o abuso e os maus tratos, entre outros.

$\mathrm{O}$ estudo dos fatores traumáticos chamados, hoje, de "fatores de risco", adquiriu relevância e significação considerando a abordagem tanto dos efeitos negativos, como das possibilidades terapêuticas. Os estudos de Freud e de autores ${ }^{1}$ posteriores conseguiram destacar a relevância do tema, significando um grande avanço científico. Olhando somente desde este ponto de vista, poderia inferir-se que os episódios pessoais e sociais traumáticos ocasionam, quase necessariamente, conseqüências negativas na psicologia e no desenvolvimento normal, pessoal e coletivo.

Nas últimas décadas, porém, alguns pesquisadores começaram a observar indivíduos e grupos que, sendo expostos a situações traumáticas, pessoais, familiares e sociais, conseguiam desenvolver-se bem e continuar

\footnotetext{
${ }^{1}$ Mesmo considerando a importância relevante da contribuição das mulheres na Igreja e no mundo, neste artigo será usado quase exclusivamente o gênero masculino para simplificar a leitura do texto.
} 
crescendo, apesar desses acontecimentos adversos. Seriam seres "invulneráveis"? Como explicar que essas pessoas contradigam o paradigma da lógica do trauma? Que fatores, internos e externos, ajudaram para que essas crianças, adolescentes, ou adultos conseguissem superar essas fortes adversidades e continuassem projetando-se sadiamente ao futuro?

O presente artigo pretende apresentar a influência da fé cristã diante deste novo paradigma que estuda a capacidade das pessoas e dos grupos de superarem as situações adversas e traumáticas e que, hoje, é conhecido como "resiliência". Este paradigma, sem desconhecer a relevância dos estudos anteriores, propõe uma mudança de ótica, centrando a observação nas capacidades dos indivíduos e grupos, de resistir e refazer-se após experiências de grandes sofrimentos. Em lugar de focar a observação nas fraquezas, sintomas, doenças, carências, tenta-se descobrir quais são os "fatores de proteção" e os "pilares de resiliência" que propiciam a promoção de forças do ambiente circundante e de capacidades pessoais para reagir e superar as adversidades da vida. Qual é o papel da crença num ser superior? A religião poderia contribuir nesse processo de recuperação de situações difíceis?

Considerando o contexto latino-americano de pobreza extrema, de exclusão social, violência e injustiça, interessa pensar de que maneira as religiões podem promover a resiliência para contribuir numa resposta melhor a estes desafios e quais as implicâncias práticas desta nova maneira de conceber. Como afirma José Tavares, é desafio das instituições e organizações de formação, diante das duras situações pelas que passam os jovens, os grupos submetidos a altos riscos, alto nível de desestruturação e estresse, promoverem atividades e experiências que ajudem a enfrentar as duras situações do dia-a-dia ${ }^{2}$.

A reflexão desta temática será feita dentro de um marco interdisciplinar, considerando as contribuições de sociólogos, pedagogos, psicanalistas, médicos, neuro-psiquiatras, etólogos, e teólogos que realizaram estudos em diferentes contextos: norte-americano, europeu e latino-americano. Cientes de que, como diz o psicanalista Claude De Tychey, "todos os trabalhos sérios sobre a resiliência insistem na dificuldade de defini-la com precisão, de delimitar o conceito e decifrar seus processos ${ }^{3 "}$, o artigo apresentará algumas aproximações ao conceito, tentando ajudar a pensar aplicações da resiliência no campo individual e social, assim como desafios e implicações deste paradigma no campo da Teologia Prática.

\footnotetext{
${ }^{2}$ Tavares. In. Tavares, 2001, p. 43.

${ }^{3}$ Tychey, 2003, p. 198.
} 


\section{Origem, definições e contextos}

Há três décadas começaram os primeiros estudos que deram origem ao que atualmente se conhece como resiliência. $\mathrm{O}$ conceito nasceu e começou a desenvolver-se com Michael Rutter, na Inglaterra e Emmy Werner, nos Estados Unidos, espalhando-se depois pela França, Países Baixos, Alemanha e Espanha. A visão norte-americana teve uma orientação principalmente comportamental, pragmática, e centrada no individual. A visão européia apresentou uma visão preferencialmente psicanalítica e assumiu uma perspectiva ética. Mais tarde, o conceito entrou na América Latina assumindo uma dimensão comunitária, desafiada pelos problemas do contexto social ${ }^{4}$.

As psicólogas norte-americanas Emmy Werner e Ruth Smith (1992, 1993), durante 32 anos, realizaram estudos na ilha de Kauai (Hawai), acompanhando 550 pessoas, que tinham padecido por pobreza extrema. Uma terceira parte delas sofreu também a dissolução do vínculo parental, alcoolismo, abuso, estresse etc. Apesar disso, 72 das 201 crianças observadas desde os dois anos de idade conseguiram superar as situações traumáticas vividas e desenvolver-se sadiamente. Considerando as que conseguiram ser resilientes mais tarde, na etapa adulta, houve quase $80 \%$ de evoluções positivas no total.

A palavra resiliência é tomada da física dos materiais. É uma força de resistência ao choque e de recuperação. Significa a capacidade elástica de um material para recobrar sua forma original depois de ter sido submetido a uma pressão deformadora.

Na psicologia,

resiliar [résilier] é recuperar-se, ir para frente depois de uma doença, um trauma ou um estresse. É vencer as provas e as crises da vida, isto é, resistir a elas primeiro e superá-las depois, para seguir vivendo o melhor possível. [...] Implica que o indivíduo traumatizado se sobrepõe [rebondit (se desenvolve depois de uma pausa)] e se (re)constitua ${ }^{5}$.

É a capacidade para desenvolver-se bem, para continuar projetando-se no futuro apesar dos acontecimentos desestabilizadores, de condições de vida difíceis e de traumas às vezes graves. É a capacidade humana universal de lidar, superar, aprender ou mesmo ser transformado com a adversidade

\footnotetext{
${ }_{5}^{4}$ Suárez Ojeda, 2004, p. 18-9.

5 Theis, 2003: 50.
} 
inevitável da vida. Esta capacidade de proteção permite a "uma pessoa, um grupo ou uma comunidade impedir, diminuir ou superar os efeitos nocivos da adversidade ${ }^{6 \prime}$. Implica tentar transformar intempéries, momentos traumáticos e situações difíceis e inevitáveis, em novas perspectivas ${ }^{7}$. Para o médico e psicanalista Aldo Melillo, é "a capacidade dos seres humanos de superar os efeitos de uma adversidade à qual estão submetidos e, inclusive, de sair fortalecidos da situação ${ }^{8, "}$

Os estudos sobre resiliência sugerem uma mudança de paradigma ao propor uma ótica de observação centrada nas capacidades dos indivíduos e grupos para a superação das experiências traumáticas, uma perspectiva de esperança. Em lugar de priorizar o enfoque dos aspectos negativos, isto é, das fraquezas, sintomas, doenças, carências e meios de compensá-los, tenta descobrir e promover as forças e capacidades para reagir e superar as adversidades da vida. Como afirmam Nan Henderson ${ }^{9}$ e Mike Milstein ${ }^{10}$, o fundamento do paradigma da resiliência questiona duramente a idéia de que os fatores de risco e as realidades traumáticas "inevitavelmente condenam as pessoas a contrair psicopatologias ou a perpetuar ciclos de pobreza, abuso, fracasso escolar ou violência ${ }^{11}$ ”. Mesmo que a formulação do conceito de resiliência seja relativamente nova, as buscas de superar as adversidades e a obtenção significativa de bons resultados são tentativas do ser humano e inquietações das religiões de todos os tempos. O primeiro que usou, em sentido figurado, o termo resiliência, foi o conhecido psicólogo John Bowlby (1992) e definiu-a assim: "recurso moral, qualidade de uma pessoa que não desanima, que não se deixa abater ${ }^{12,}$.

No início dos estudos, alguns autores começaram utilizando o termo invulnerabilidade, pois se observava que algumas crianças pareciam recuperar-se das adversidades, voltando a um estado anterior como se não tivessem sido atingidas. Porém, logo se considerou o termo incorreto, pois o ser humano é, por condição, vulnerável e, sob o ponto de vista psicológico, nunca fica igual após uma experiência dura de vida. Uma expressão significativa e

\footnotetext{
${ }^{6}$ Theis, 2003, p. 50.

${ }^{7}$ Assis, 2006, p. 57.

${ }^{8}$ Melillo, 2004, p. 63.

${ }^{9}$ Henderson é professora universitária, Mestre em Trabalho Social.

${ }^{10}$ Milstein é professor emérito de Liderazgo Educacional no México. Escreveu onze livros e colaborou ativamente em projetos relativos à resiliência.

${ }^{11}$ Henderson, 2003, p. 20.

${ }^{12}$ Manciaux, 2003, p. 20.
} 
mais exata seria a que Grunspun ${ }^{13}$ propõe ao falar em resiliência como a capacidade humana de "ser imune psicologicamente" diante da violência de outros ou diante ao estresse provocado por catástrofes naturais ${ }^{14}$.

A resiliência, conceito já amplamente estudado sob o ponto de vista das capacidades da pessoa, ampliou-se. No contexto latino-americano, especialmente no CIER, ${ }^{15}$ estuda-se resiliência em projetos sociais e recentemente resiliência comunitária, isto é, a capacidade de um povo, dos integrantes de uma cidade ou nação de superar coletivamente situações adversas.

O paradigma da resiliência não é uma técnica nem uma solução mágica. É um saber interdisciplinar no qual convergem diferentes áreas e setores: ciências humanas, ciências da saúde, e administração entre outras. Há, no entanto, poucos autores que se detêm para descrever como a fé, a espiritualidade, ou a pertença a um grupo, comunidade ou instituição religiosa influenciam na hora da superação das dificuldades e sofrimentos pessoais e sociais. É verdade que há vários trabalhos nas áreas da pedagogia, psicologia, saúde, etc. com menções ao assunto, mas há pouca literatura relacionada especificamente ao campo religioso.

\section{Características da resiliência}

A resiliência é uma capacidade que todo ser humano tem, em maior ou menor medida. É um recurso que é, em parte, inato, mas também se adquire ao longo do tempo, pois a resiliência, como diz Cyrunlik ${ }^{16}$ (1999), "se tece" durante todo o ciclo vital. Pode ir crescendo, ajudada pelas situações e condições externas, isto é, por um entorno que a favoreça. As atitudes resilientes podem ser promovidas, com o apoio de pessoas ou instituições (família, igreja, escola, centro de saúde, organizações ou associações sociais ou políticas etc.), que se preocupam em motivar a ativação das capacidades de superação das dificuldades. Pensa-se na ação preventiva e na promoção, ou seja, como fomentá-la no ambiente familiar, social, de trabalho e de missão

\footnotetext{
${ }^{13}$ Gruspun é professor de Psicopatologia da Infância na PUC-SP.

${ }^{14}$ Grunspun, 2005, p. 1.

${ }^{15}$ CIER - Centro Internacional de Información y Estudios de Resiliencia, que funciona na Universidade de Lanús, Buenos Aires, Argentina.

${ }^{16}$ Cyrulnik é neuropsiquiatra, psicanalista, etólogo. Aos seis anos de idade, fugiu de um campo de concentração.
} 
mediante a educação, das intervenções sociais, das políticas públicas, assim como dos projetos comunitários civis ou eclesiais.

A resiliência não é uma realidade alcançada para sempre, não é absoluta, mas dinâmica. Por isso, não se deveria dizer que uma pessoa é resiliente, ou não é resiliente, já que cada um tem momentos e circunstâncias da vida em que consegue lidar melhor com as dificuldades. Depende de vários fatores, entre outros o ciclo vital, o apoio externo, a cultura. Ao observar a resiliência de alguém, percebe-se que certos processos de recuperação e superação podem ser mais rápidos que outros, dependendo das situações e das pessoas. Inclusive, alguns traumas que parecem menos graves podem mobilizar outros conflitos anteriores ainda não resolvidos, ocasionando o efeito chamado "gatilho". Por isso, as capacidades de superação dependem de como a pessoa vivenciou e elaborou outras experiências traumáticas.

As fortalezas ou vulnerabilidades também variam conforme o tipo de problema que se apresenta, pois a percepção do que pode ser considerado grave ou sofrido é subjetiva. Daí a importância de ouvir o relato de como cada adversidade é sentida, interpretada e contada pelo próprio indivíduo, pois "apenas ele próprio pode narrar e avaliar o que lhe aconteceu" ${ }^{17}$ ". Além da linguagem verbal, "a narrativa passa também por outras fontes, [...] como os gestos e os sentidos manifestos e ocultos presentes na interação huma$\mathrm{na}^{18 \%}$.

Considera-se que a superação de algum trauma ou adversidade faz crescer a própria resiliência, mas mesmo que, para algumas pessoas, determinadas adversidades chegam a contribuir no amadurecimento como ser humano, na descoberta de um sentido mais profundo dado às coisas e a vida, assim como a percepção dos valores e a visão do mundo, contudo, precisa afirmar-se que as adversidades "isoladamente são insuficientes para promovê-la ${ }^{19}$.

As capacidades resilientes dos seres humanos e dos grupos, por mais promovidas e desenvolvidas que estejam, não são ilimitadas. Todo ser humano tem um limite pessoal para lidar com a adversidade. Conforme as afirmações do psicanalista Claude de Tychey, citando Bourguignon, "diante de sucessos massivamente destruidores "não há imunidade ao estresse, porém só diferentes modelos de resposta melhor ou pior adaptados' [...] mas, mesmo conseguindo reagir 'essa sobrevivência tem um preço ${ }^{20, "}$.

\footnotetext{
${ }^{17}$ Assis, 2006, p. 2.

${ }^{18}$ Assis, 2006, p. 2.

${ }^{19}$ Assis, 2006, p. 57.

${ }^{20}$ Lecomte, 2003, p. 191.
} 
Para potencializar a resiliência de um grupo ou de uma pessoa, é preciso descobrir os chamados pilares de resiliência, isto é, os recursos próprios da pessoa, e os fatores de proteção do meio circundante, ou seja, as capacidades que há na família, no ambiente ou na instituição educativa, social, política ou religiosa. Esse processo de fortalecimento e capacitação é conhecido hoje como empoderamento (empowerment) e preocupa-se em "identificar os recursos, revelá-los a quem os possui - que freqüentemente não sabe que os possui - e ajudá-lo a aplicá-los ${ }^{21}$.

A resiliência é considerada como o resultado final de "processos de proteção" que não eliminam os riscos experimentados, mas encorajam o indivíduo a lidar efetivamente com a situação sofrida e a sair fortalecido dela. Os processos de proteção têm quatro funções principais: reduzir o impacto dos riscos experimentados, alterando a exposição da pessoa à situação adversa; reduzir as reações negativas em cadeia que seguem a exposição do indivíduo à situação de risco; estabelecer e manter a auto-estima e a auto-eficácia pelo estabelecimento de relações de apego seguras e o cumprimento de tarefas com sucesso; criar oportunidade para reverter os efeitos de estresse ${ }^{22}$.

\section{Espaços para a promoção da resiliência}

Em 1995, o sociólogo e demógrafo Stefan Vanistendael, do BICE, ${ }^{23}$ baseando-se em pesquisas e experiências práticas, enunciou os cinco âmbitos principais para a promoção da resiliência em crianças e que estão interrelacionados entre si. São os seguintes: redes de apoio social, em especial a aceitação incondicional da criança; o sentido da vida, vinculado à vida espiritual e à fé religiosa; as aptidões e o sentimento de controle da própria vida; a auto-estima; e o senso de humor. O autor também esclarece que esses itens podem ser ampliados ${ }^{24}$.

Em 1996, para que fosse mais bem compreendido o tema, Vanistendeal criou uma metáfora que chamou "la casita" (a casinha) e assim, sem traduzir o termo, foi transmitido para as diferentes línguas. Com esse forte símbolo, ele quis sintetizar de uma maneira simples e gráfica a compreensão dos

\footnotetext{
${ }^{21}$ Henderson, 2003, p. 20.

${ }^{22}$ Rutter, 1987. Apud. ASSIS, 2006, p. 63.

${ }^{23}$ Vanistendael é secretário do Bureau International Catholique de l' Enfance, uma ONG que defende a dignidade e o interesse superior da criança.

${ }^{24}$ Vanistendael, 1995, p. 6.
} 
resultados de estudos, observações e experiências por meio de um modelo confrontado em quinze países, com diferentes culturas, de quatro continentes.

\section{LA CASITA}

Uma síntese de alguns elementos para a construção da Resiliência

(Stefan Vanistendael - casitafr - BICE 1996)

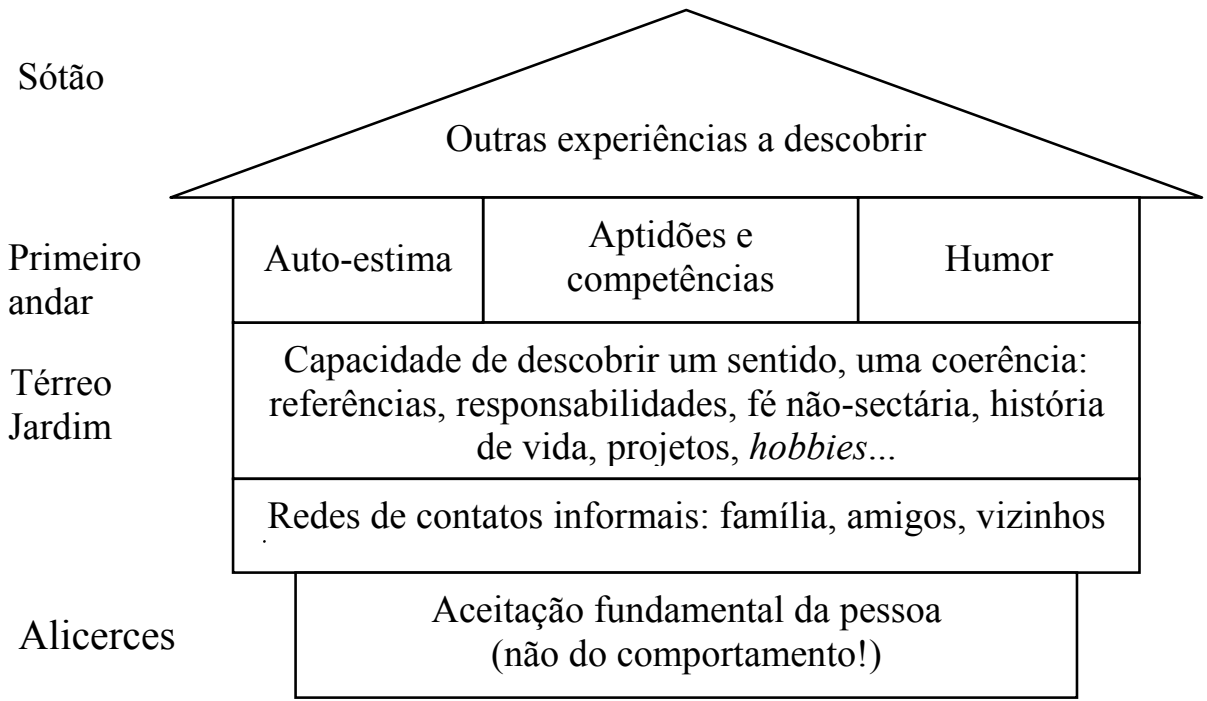

Solo: necessidades físicas básicas

(segurança física, saúde, alimentação, sono etc.)

O desenho de cada casita é dinâmico e varia conforme as culturas e as realidades pessoais e coletivas. Pode aplicar-se à análise de um determinado grupo religioso, auxiliando a discernir em que domínio, ou peça da casa, seria importante incentivar os esforços, o que permitiria enxergar tanto os elementos que podem ser construídos quanto visualizar os elementos da casita, que foram fragilizados ou destruídos.

Descreveremos brevemente alguns destes elementos que poderiam ser considerados fatores de proteção, pois ajudam na superação das dificuldades, isto é, favorecem a resiliência.

\subsection{Figuras significativas e promotoras de resiliência}

$\mathrm{O}$ aspecto mais especial e original do enfoque da resiliência, como afirma Aldo Melillo "é a ênfase na necessidade do outro como ponto de apoio 
para a superação da adversidade ${ }^{25}$ ". Tanto na observação quanto nos depoimentos de crianças, jovens e adultos resilientes, há um dado comum e significativo: todos e todas reconhecem o apoio irrestrito de pelo menos uma pessoa significativa. Pode ser tanto um jovem como um adulto, membro da família, quanto um amigo, educador, religioso, ou agente de saúde. Um traço comum destas figuras significativas na vida da pessoa que sofre é o fato de elas transmitirem sua aceitação incondicional da pessoa que passa por uma situação difícil, mas aceitação da pessoa não significa aceitar todo e qualquer comportamento.

Esse dado coincide com as observações no campo da psicologia do desenvolvimento, pois, nos primeiros tempos de vida, constata-se a importância da figura que ocupa o papel principalmente materno (mãe biológica ou não) para garantir o crescimento sadio, a formação da identidade e o aprendizado da elaboração das frustrações. O ser humano é influenciado pelas expectativas e pelo olhar dos outros, não só da mãe, mas também de outros familiares, dos amigos, dos vizinhos, dos educadores e da sociedade. John Bowlby salienta que o apoio, a confiança, o amor são indispensáveis ao longo da vida, e que esse entorno afetivo é um aspecto determinante para se proteger das adversidades, não só na infância. Afirma esse autor: "Acumulam-se evidências de que seres humanos de todas as idades são mais felizes e mais capazes de desenvolver seus talentos quando estão seguros de que, por trás deles, existem uma ou mais pessoas que virão em sua ajuda caso surjam dificuldades ${ }^{26}$,

O psicólogo inglês Donald Winnicott, falando do papel da figura materna, afirma que não deve ser "perfeita", e sim "suficientemente boa". Assis precisa que o entorno afetivo e material para proteger uma criança deveria ser "estável, amoroso, confiável, flexível, aberto, firme o suficiente para facilitar a introjeção de limites e normas culturais, respeitoso", porém "esse entorno nunca é perfeito nem invulnerável ${ }^{27}$ ". Isso só acontece quando há pelo menos uma ou mais pessoas significativas que mantêm com a criança, adolescente ou adulto que sofre, um vínculo positivo forte com alguém que acredita no potencial da pessoa, que sabe ouvi-la e ter com ela um vínculo suficientemente empático para ajudá-la a desenvolver suas capacidades de superação.

Ầs pessoas que dão esse apoio incondicional são chamados por Cyrunlik e outros autores de tutores de resiliência ou tutores de desenvolvimento, pois permitem que o processo continue sem que fiquem traumas que

\footnotetext{
${ }^{25}$ Melillo, 2004, p. 64.

${ }^{26}$ Bowlby, 2001, p. 139.

${ }^{27}$ Assis, 2006, p. 61.
} 
atrapalhem o crescimento ou a vida adulta. Não se entende por tutor uma figura paternalista, mas alguém que, aceitando incondicionalmente a pessoa que está numa situação dolorosa, promove nela a confiança, a segurança e a esperança de que é possível superar a dificuldade, de que vale a pena lutar, de que é possível encontrar outra forma de lidar com o problema e até de achar um sentido, um motivo para melhorar. Usando um termo winnicottiano, esse apoio irrestrito opera como "continente" (holding), que motiva o crescimento exatamente no meio da situação conflitante, pois se trata de uma figura que promove a liberdade e a responsabilidade da pessoa que está em estado mais vulnerável, para ela poder superar a situação difícil.

Outras vezes, não é só uma pessoa, mas uma "rede de proteção" [filet de protection], um "invólucro" [envoltura] ${ }^{28}$ composto por várias pessoas que garantem uma continuidade no apoio social, cuidando para que a rede não seja demasiado apertada com o risco de tornar rígido e limitar, nem tão frouxa que não consiga dar suporte, contenção. Em vários âmbitos, sobretudo religiosos, constatam-se vários depoimentos de pessoas que passaram por situações difíceis e que, sentindo-se acolhidas com carinho e compreensão, escutadas, valorizadas, aceitas sem condições, encontram conforto, capacidade e esperança para assumir com sentido e esperança as dificuldades e os sofrimentos. Várias delas relatam que a experiência de sentir-se reconhecidas, amadas e cuidadas, por Deus, pelas pessoas, pelo grupo ou comunidade religiosa, foi fonte de fortalecimento humano e espiritual, de superação da adversidade, e uma ajuda que potencializou o processo de cura interior. Também nos relatos bíblicos podem descobrir-se exemplos de resiliência. A parábola do filho pródigo, tão bem representada na pintura de Rembrandt, expressa o significado profundo desta aceitação incondiciona ${ }^{29}$.

Analisando-se casos de pessoas que conseguiram superar as situações adversas e outras que não, observa-se a importância da acolhida na escuta. Aqueles que sofreram violência, mas, ao falar, tiveram a sensação de não serem escutados, reviveram a sensação do trauma; ao contrário, aqueles que sentiram receptividade na escuta, quando narraram o que padeceram, "começaram a perceber um sentimento de auto-estima, pertença e contenção ${ }^{30 "}$ ". A falta de apoio pode acontecer "seja por não conseguirem solicitá-lo, seja por realmente não contarem com uma rede de proteção ${ }^{31 "}$.

\footnotetext{
${ }^{28}$ Michaud, 2003, p. 82.

${ }^{29}$ Vanistendael, 1994, p. 4-5.

${ }^{30}$ Melillo, 2004, p. 74.

${ }^{31}$ Assis, 2006, p. 59.
} 


\subsection{Aptidões pessoais}

Quase sempre, a resiliência está associada a uma boa auto-estima. A1gumas pesquisas parecem demonstrar que a aceitação de si é uma das poucas condições quase indispensáveis para o desenvolvimento da resiliência. "A convivência com o sentimento de desvalorização pessoal parece ser um dos poucos eventos adversos que, por si só, têm capacidade de afetar o potencial de superação de problemas ${ }^{32, " . ~ P a r a ~ o ~ f i l o ́ s o f o ~ e ~ t e o ́ l o g o ~ p r o t e s t a n t e ~ E r i c ~}$ Fuchs, ${ }^{33}$ considerando a importância da aceitação e do reconhecimento dos outros, a resiliência é um sinal da "importância estruturadora da confiança", pois "a auto-estima se baseia na estima que o próximo lhe demonstra" Cabe perguntar como no âmbito de cada religião é cultivada a confiança e auto-estima.

As pessoas que são mais sociáveis e que conseguem estabelecer diferentes relações formais e informais de apoio com pessoas, até de diferentes ambientes e idades, estão em melhores condições para encontrar ajuda, sempre que possam eventualmente estabelecer um vínculo de suficiente confiança. São pessoas que, com certa naturalidade, despertam simpatia nos outros e que mais facilmente conseguem apoio social.

Além do temperamento e da personalidade de cada um, pode promover-se a resiliência, motivando as pessoas que sofrem a não se isolar a fim de compartilhar com outros as preocupações, assim como alentá-las a pedir ajuda $^{35}$. Um instrumento significativo para isso são os grupos de apoio de pessoas que padecem um mesmo tipo de sofrimento, seja por situações pessoais diretas, seja por vínculos bem próximos, por exemplo, imigrantes, sobreviventes de tragédias naturais ou guerras, doentes de um tipo semelhante de enfermidades ou dependências, portadores de deficiência, enlutados, familiares de alcoólatras, entre outros. Muitos destes grupos são promovidos e funcionam nos locais das igrejas e casas religiosas.

No processo de desenvolvimento psicológico, são as figuras parentais e posteriormente os educadores os que possibilitam o aprendizado dos limites, do controle dos impulsos, da aceitação dos erros, e a tolerância das frustrações, isto é, a introjeção de normas de conduta tanto para um convívio social sadio como para possibilitar um crescimento pessoal e o desenvolvimento das virtudes, como o controle de si. Por isso, um fator protetor, que

\footnotetext{
${ }^{32}$ Assis, 2006, p. 49.

${ }^{33}$ Fuchs é catedrático emérito da Faculdade de Teologia Protestante da Universidade de Genebra, Suíça.

${ }^{34}$ Fuchs, 2003, p. 286.

${ }^{35}$ Michaud, 2003, p. 82.
} 
deve ser promovido desde a idade infantil, é o da assunção de responsabilidades e o estabelecimento de expectativas suficientemente elevadas, claras e compatíveis com o ciclo vital e as possibilidades de pessoa. As capacidades de iniciativa, protagonismo e criatividade para resolver as situações adversas mostram-se como elementos favorecedores para a superação das dificuldades. Trata-se de valores e atitudes promovidos em alguns grupos religiosos, porém, não em todos.

Por último, e não menos importante, um pilar de resiliência é o senso de humor diante da adversidade. Não deve ser confundido com um simples mecanismo de evasão, pois o senso do humor tem a capacidade de trazer a realidade dolorosa e incorporá-la ao quotidiano, convertendo-a "em algo

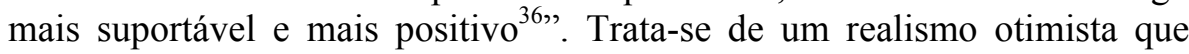
demonstra esperança mesmo diante de uma situação trágica na qual é possível encontrar algo absurdo, incongruente e até cômico.

Essa capacidade de aceitar e até rir do que é imperfeito demonstra a faculdade psíquica de tomar distância do assunto, permitindo lidar melhor com a dificuldade, pois olhando deste outro ângulo é possível enxergar diferente e com menos sentimento a realidade que faz doer. Para isso é importante o clima afetivo e de confiança que há no entorno. Essa capacidade de criatividade na leitura e na verbalização dos fatos com bom humor, também se vê favorecida pelas atividades artísticas e lúdicas, sendo a dança, a música, a poesia, o espírito celebrativo, assim como o jogo de palavras, ou outro tipo de jogos, instâncias propícias para a promoção da resiliência.

Essas observações aplicam-se tanto para as dificuldades quotidianas como para situações mais dramáticas. Por exemplo, no caso dos sobreviventes de terremotos, destaca-se que uma das características para detectar as crianças e adolescentes com maior capacidade de se recompor após a tragédia, é o senso do humor. Geralmente, aqueles que mostram esta atitude pessoal coincidentemente são mais resistentes às dificuldades e também mais capazes de se tornarem líderes e promotores de resiliência em outras pessoas.

Como característica social, o humor de um grupo ou de um povo tem ajudado também em situações de falta de liberdade, por exemplo, em realidades políticas opressivas, possibilitando uma fala das adversidades, contribuindo para a exteriorização do sofrimento, e para a busca criativa de estratégias e de saídas melhores.

$\mathrm{Na}$ literatura sobre resiliência, não foram encontrados estudos sobre o humor nas diferentes religiões. Contudo, Vanistendael, fala do humor em

${ }^{36}$ Vanistendael, 1995, p. 26. 
Jesus dizendo: "Esse dom que coloca os homens à vontade com o universo e com Deus, que os impulsiona para procurar mais longe, para regozijar-se com o mundo e com Deus ${ }^{37, "}$.

Jacques Lecomte ${ }^{38}$ se interessou pelo estudo de outro fator importante a ser analisado na resiliência: como administrar uma função tão presente diante da adversidade: a memória. Tanto na educação de crianças e jovens como no acompanhamento de pessoas que passam por momentos difíceis ou traumáticos, parece ser necessário ter um manejo especial tanto da memória quanto do esquecimento. Observa-se que quem é consciente e lembra do sofrimento vivido tentará evitar reproduzi-lo em outras situações. No entanto, não são poucos os casos de pessoas que descobriram nessa dor um incentivo para servir a outras pessoas que passam por situações traumáticas. Certo esquecimento se faz necessário para não cair no perigo de dar demasiada importância às lembranças dolorosas, pois "poderiam levar ao desespero e à sede de vingança" ${ }^{39}$ ", assim como a uma excessiva tristeza e falta de criatividade para continuar na caminhada. É preciso esquecer um pouco das lembranças dolorosas, para que não invadam a vida psicológica nem interfiram na vida do grupo.

\subsection{Espiritualidade e sentido}

A literatura sobre resiliência ainda é pouco exaustiva ao falar de religiosidade, fé ou espiritualidade. Nem todos os autores abordam a temática. No entanto, alguns, em especial Vanistendael, desenvolvem com marcada ênfase esse aspecto. Consideram que o sentido da vida como pilar de resiliência pode estar vinculado a uma filosofia de vida e, muitas vezes, à vida espiritual e à fé religiosa.

Vários autores concordam em que a vivência da religião e a participação na Igreja são fatores de proteção, pois ajudam tanto a assumir com aceitação as adversidades inevitáveis, quanto a lutar com esperança por uma transformação ${ }^{40}$. Grunspum salienta que "[a] espiritualidade com suporte congregacional permite suportar crises e superar com recuperação", já que na confiança na presença divina é possível até "crescer com a adversidade, sentindo que não tem somente a força dos homens, mas uma força

\footnotetext{
${ }^{37}$ Vanistendael, 1995, p. 26.

${ }^{38}$ Lecomte é ex-jornalista científico, doutorando em Psicologia ambiental na Universidade de Paris V, França.

${ }^{39}$ Lecomte, 2003, p. 212

${ }^{40}$ Assis, 2006, p. 106.
} 
superior ${ }^{41}$ ". Para Walsh, "a religião e a espiritualidade podem ser recursos terapêuticos poderosos para recuperação, cura e resiliência ${ }^{42 "}$.

Grunspun afirma, que "crer, acreditar, perdoar em nome de Deus é a construção de escudo protetor importante para adquirir resiliência na vida ${ }^{43}$ ", Observa que a família resiliente compartilha valores além dos seus interesses imediatos, que estão fundamentados numa moral e numa ética e "que correspondem ao bem-estar grupal, tradição sociocultural, em costumes morais e leis transmitidas por gerações". Ele destaca o efeito positivo do tempo compartilhado em família destinado para a oração e as celebrações religiosas como o shabat, a missa, culto e a escola dominical, entre outras atividades ${ }^{44}$.

Vanistendael salienta que as "pesquisas científicas logo constataram correlações positivas entre a fé religiosa e a resiliência ${ }^{45}$ ". Contudo, ele sugere ter prudência na hora de afirmar este correlato, especialmente quando se trata de uma fé que ele chama sectária, pois caso a fé induza à violência contra si ou contra outros, esse tipo de espiritualidade ou crença religiosa não poderá considerar-se promotora de resiliência, já que a resiliência é necessariamente um "processo de crescimento da vida" ${ }^{46 "}$. Vale destacar que os traços sectários não devem identificar-se com as religiões não oficiais.

Diante de um acontecimento traumático, normalmente existem etapas marcadas por duas interrogações que apontam à descoberta de um sentido em relação ao sofrimento. Vanistendael, citando Lecomte, precisa que a primeira questiona em relação ao passado. É uma resposta à pergunta: "por que isso me aconteceu?". A segunda se refere ao futuro, e tenta responder à pergunta: "para que isso me aconteceu? $?^{47}$ ". A pergunta pelo por que remete a buscar o sentido nas causas, ajuda a esclarecer a verdadeira origem da situação traumática e a não se atribuírem falsas culpabilidades. Em algumas oportunidades, não chega a ser necessário encontrar um sentido especial, sendo suficiente narrar o acontecimento doloroso. A segunda pergunta e a sua resposta podem ajudar a descobrir, justamente na vivência dolorosa, o início de um novo sentido dado pela fé em Deus, assim como podem desenvolver o desejo de um compromisso construtivo. Como diz Vanistendael: "Mais de uma pérola se formou ao redor de uma ferida, como na ostra ${ }^{48,}$.

\footnotetext{
${ }^{41}$ Grunspun, 2005, p. 143.

${ }^{42}$ Walsh, 2005, p. 7.

${ }^{43}$ Grunspun, 2005, p. 159.

${ }^{44}$ Grunspun, 2005, p. 136.

${ }^{45}$ Vanistendael, 2005, p. 11-12.

${ }^{46}$ Vanistendael, 2005, p. 12

${ }^{47}$ Vanistendael, 2005, p. 12

${ }^{48}$ Vanistendael, 2005, p. 12.
} 
A psicologia demonstra que para o ser humano não é possível superar completamente as situações traumáticas a ponto de apagá-las. Como afirma Cyrulnik, sempre permanece "um vestígio", mas pode encontrar-se outra forma de vivê-las, dando-lhes um sentido, "uma outra vida, mais suportável e, por vezes, bela e sensata". ${ }^{49} \mathrm{Um}$ dos autores que marca mais claramente a importância da busca do sentido da vida, especialmente nas situações mais extremas é Viktor Frankl que, tendo sobrevivido depois de quatro campos de concentração e da perda dos pais, da esposa e do filho por extermínio, escreveu um livro famoso no qual explicita uma nova abordagem terapêutica: a logoterapia, isto é, a cura através do sentido ${ }^{50}$.

Ter ou reconstituir um vínculo positivo com a vida é, para algumas pessoas, algo quase intuitivo, mas para outras pode ser acrescentado pelos vínculos familiares e com amigos, assim como mediante o engajamento no serviço a outras pessoas ${ }^{51}$. Não são poucos os relatos de pessoas que afirmam que só uma forte experiência de amor, humano ou divino, conseguiu dar-lhes novamente uma razão para lutarem e para continuarem a vida, oferecendo-lhes um sentido para viver e superar-se. São depoimentos que, às vezes, se escutam não só em casos de perdas graves ou doenças, mas também em situações físicas aparentemente irreversíveis como pode ser o uso de drogas pesadas.

A pergunta pelo por que na pessoa religiosa freqüentemente é dirigida também a Deus. Brota naturalmente do contato com o sofrimento inocente e leva à busca de uma resposta. O ser humano sofre ainda mais quando não encontra uma resposta satisfatória. Assim comenta o Papa João Paulo II, na Carta Apostólica Salvici Doloris ${ }^{52}$, sobre o sentido cristão do sofrimento humano, escrita depois do atentado que sofreu. Nessa mesma perspectiva, deparamo-nos com o que Frankl chama "valores de atitude" para significar aqueles valores ou sentidos que são necessários encontrar para assumir e aceitar os sofrimentos que não são possíveis de evitar.

Desde o enfoque da resiliência, questiona-se a legitimidade de algumas ações escolhidas como sobrevivência, afirmando-se que deveria haver uma referência dupla: o bem-estar próprio e bem-estar do outro. Por isso, a pessoa que resolve seus problemas mediante corrupção, engano ou violência, não poderia ser considerada resiliente porque ela estaria prejudicando terceiros. Neste sentido, cabe analisar quais são os valores defendidos pelas

\footnotetext{
${ }^{49}$ Cyrulnik, 2003, p. 24. Em outra tradução da mesma obra: "às vezes, até bonita e com sentido".

${ }^{50}$ Frankl, 1981.

${ }^{51}$ Vanistendael, 2004, p. 93-95.

52 Juan Pablo II, 1984, n. 9.
} 
religiões e até que ponto algumas religiões, por exemplos as fundamentalistas, consideram estes dois parâmetros.

Relacionada à atitude ética, psicológica e à memória, vincula-se a temática do perdão. Não se trata de uma desculpa para o sofrimento, dano ou ofensa recebida, e sim para "desbloquear o desenvolvimento do crescimento", tanto na pessoa que dá o perdão quanto na que o aceita ${ }^{53}$. Trata-se de um reconhecimento do mal feito ou recebido; é uma atitude que brota da decisão e não pressupõe ter sentimentos positivos em relação ao agressor. Como diz Vanistendael, a pessoa afetada "compreende também que nós não podemos bloquear a vida sob esse mal, senão o mal será mais uma vez vencedor". Para poder tecer um futuro sadio, é necessário considerar o passado, mas sabendo que "a cura dos sentimentos pode evoluir em paralelo ao processo de perdão, às vezes acompanhando-o, às vezes, precedendo-o, às vezes sucedendo-o ${ }^{54}$,

\section{Conclusão}

Finalmente, a resiliência desafia e impulsiona a Teologia para assumir conscientemente a necessidade de situar-se numa perspectiva de esperança e questiona as visões deterministas e pessimistas de alguns grupos cristãos. Num marco social de "dor exacerbada" pela crescente exclusão social, "a promoção da resiliência se torna uma necessidade e uma obrigação". Cientes do sofrimento de tantas pessoas, o paradigma da resiliência desafia a observação, o estudo e a criatividade dos cristãos e cristãs, dos teólogos e teólogas, dos agentes de pastoral e dos pesquisadores para descobrir como promovê-la nos mais diversos contextos e, sobretudo, no campo da reflexão e da Prática Pastoral.

O caminho está já traçado, pois a resiliência é a experiência até natural de tantas pessoas que conseguiram, ao longo da história, crescer, superar-se, refazer-se, ainda quando parecia que não havia mais saída. Como diz Vanistendael, "talvez a resiliência seja a prefiguração mais natural da dinâmica da cruz e da ressurreição ${ }^{55 "}$.

Do ponto de vista da Teologia Prática, o enfoque da resiliência vem ao encontro do desafio de achar melhores perspectivas de compreensão e de ação para auxiliar as pessoas que padecem sofrimentos. O estudo da resiliência contribui na superação das adversidades individuais e comunitárias, e pode ser aplicado no campo pessoal, social, laboral e religioso. Supõe

\footnotetext{
${ }^{53}$ Vanistendael, 2003, p. 29.

${ }^{54}$ Vanistendael, 2005, p. 13.

${ }^{55}$ Vanistendael, 1995, p. 26.
} 
investigar as forças de recuperação de cada pessoa e grupo e ver como melhor desenvolvê-las.

A resiliência convida a olhar positivamente para aqueles e aquelas que passaram por situações de risco e adversidades sérias para modificar as práticas educativas, o enfoque do trabalho social ou da área da saúde, do trabalho pastoral ou de orientação, começando por observar, identificar, e usar melhor os recursos daqueles que sofrem. O papel dos estudiosos das religiões e dos profissionais que acompanham pessoas que já passaram por situações duras, precisa enriquecer-se com um número crescente de estudos interdisciplinares sobre resiliência assim como tirar lições da experiência das pessoas resilientes das diferentes idades, contextos, culturas e religiões, para ver o que lhes permitiu superar a adversidade.

$\mathrm{Na}$ análise dos chamados fatores de proteção que contribuem para potencializar a resiliência, consideram-se tanto os recursos próprios da pessoa como os recursos que há na família, no ambiente ou instituição educativa, social, política ou religiosa. Constata-se, em primeiro lugar, o papel de uma ou mais figuras significativas que garantem uma acolhida e aceitação incondicional e um entorno favorável. Observa-se também a influência positiva das qualidades pessoais, como auto-estima, sociabilidade, responsabilidade e senso de humor, e a importância fundamental do sentido de vida vinculado à vida espiritual e as crenças religiosas. A fé, vivida com confiança em um Deus presente e força que ajuda a superar o sofrimento, parece ser uma chave no desenvolvimento das capacidades de resiliência. Daí as implicâncias para o contexto religioso, lugar privilegiado para acompanhar esse processo, desafiando os estudiosos e a comunidade de fé a redimensionar com esta ótica tantos recursos pessoais e comunitários que podem ser oferecidos por meio das celebrações, dos variados serviços, práticas e atividades religiosas.

Conclui-se com a observação de alguns autores e promotores de resiliência, afirmando que ao pesquisar e ao trabalhar na promoção da resiliência também os estudiosos, os profissionais e colaboradores tornam-se mais resilientes.

Susana María Rocca Larrosa

Graduada em Psicologia pela Universidad Católica del Uruguay, Doutoranda em Teologia Prática pelas Faculdades EST-São Leopoldo/RS. e-mail: srocca@unisinos.br 